\title{
PERTANGGUNGJAWABAN PENGGANTI DALAM HUKUM PAJAK DI INDONESIA*
}

\author{
Henry Dianto Pardamean Sinaga \\ Kanwil DJP Kalimantan Barat, \\ Jalan Jenderal Ahmad Yani No. 1, Pontianak, Kalimantan Barat \\ sinagahenrydp@gmail.com.
}

\begin{abstract}
Generally, the avoidance of taxes in a business gives benefit for principals within the cooperation with his/her agent. The formulation of the problem is First, What is the replacement liability in the formation of tax law in Indonesia? Second, What is the liability of WP's substitution in tax law enforcement in Indonesia? This normative juridical research uses descriptive-comparativeprescriptive in solving the existing problems. In order to tackle and or to restore on state tax revenues losses, it is expected that future tax (penal) law should regulate vicarious liability and its criteria explicitly, and widening the scope of "any one" including individual and corporation.
\end{abstract}

Keywords: Taxpayer, Corporate, Vicarious Liability, Adminstrative, Penalty.

\begin{abstract}
Abstrak
Penghindaran pajak yang terjadi dalam suatu lingkungan usaha yang umumnya menguntungkan prinsipal tidak dapat terlepas dari adanya kerjasama dengan agennya. Rumusan masalahnya yaitu Pertama, Bagaimana pertanggungjawaban pengganti dalam pembentukan hukum pajak di Indonesia? Kedua, Bagaimana pertanggungjawaban pengganti WP dalam penegakan hukum pajak di Indonesia? Penelitian ini dengan metode yuridis normatif ini menggunakan pendekatan deskriptif - komparatif - preskriptif dalam menjawab permasalahan yang ada. Agar dapat menanggulangi dan atau memulihkan kerugian pendapatan negara dari pajak, diharapkan adanya pengaturan secara tegas pertanggungjawaban pengganti dan kriterianya serta adanya perluasan pengertian "setiap orang" yang mencakup manusia dan korporasi dalam peraturan perundangundangan perpajakan kedepan di Indonesia.
\end{abstract}

Kata Kunci: Wajib Pajak, Badan, Pertanggungjawaban Pengganti, Administrasi, Sanksi.

\section{A. Pendahuluan}

1. Latar Belakang Permasalahan

Penghindaran pajak dalam suatu lingkungan usaha (business) merupakan aktifitas illegal menimbulkan kerugian pada pendapatan negara akibat berkurangnya penerimaan pajak. Terjadinya penghindaran pajak ini juga menegaskan bahwa ada pihak yang diuntungkan, yaitu prinsipal (principal). Dalam memperoleh manfaat atas penghindaran pajak tersebut, prinsipal selalu membutuhkan kerjasama dari para agennya (agent) (Fabio Privileggi, Carla Marchese, dan Alberto Cassone, 2001) sebagaimana dikemukakan Kraakman, tidak dapat terlepas dari peran agen sebagai "gatekeeper" yang bertanggungjawab kepada prinsipal dalam mencegah terjadinya pelanggaran dalam kegiatan usaha. Laffont dan Tirole (JeanJacques Laffont dan Jean Tirole, 1992) dan Privileggi et.al (Fabio Privileggi, Carla Marchese, dan Alberto Cassone, 2001) mengemukakan bahwa "gatekeeper", demi kepentingan prinsipal, berperan dalam penghindaran pajak dengan melakukan manipulasi akuntansi. Chyz dan White dan

\footnotetext{
* Penelitian ini merupakan kajian ilmiah pribadi peneliti dan tidak mencerminkan pendapat/kebijakan institusi.
} 
Desai dan Dharmapala menyimpulkan adanya interaksi antara penghindaran pajak dengan konflik keagenan yang berhubungan dengan kinerja pembukuan (James A. Chyz dan Scott D. White, 2014) serta adanya tata kelola perusahaan yang kemungkinan menganjurkan terjalinnya penghindaran pajak dengan upaya manajerial untuk menambah/menciptakan nilai perusahaan (Mihir A. Desai dan Dhammika Dharmapala, 2009) kepada para pemegang saham. Pada prakteknya dalam suatu hieararki principalauditor-manager, principal memungkiri kerjasama dalam aktivitas ilegal tersebut dengan berdalih bahwa agen melakukan pelanggaran tanpa sepengetahuan prinsipal. Namun sebenarnya hal tersebut dapat terbantahkan karena secara alamiah, prinsipal selalu menginginkan kinerja maksimal para agennya, termasuk manajer, sehingga dalam mengelola adanya keterbatasan informasi dari para agen, prinsipal mempergunakan internal auditor. Bahkan, dalam mengantisipasi ketidakpatuhan manajer yang dapat mengarah pada terjadinya kolusi dan penyuapan antara manajer dengan internal auditor, prinsipal dapat menyewa eksternal auditor untuk mengawasi kinerja internal auditor dan agen (Fred Kofman dan Jacques Lawarree, 1993).

Aktifitas penghindaran pajak yang menimbulkan kerugian negara yang menyangkut hubungan principal-agen, juga semakin memprihatinkan di Indonesia. Salah satu contoh kasus adalah putusan kasasi Mahkamah Agung (MA) atas pidana pajak tax manager AAG yang merugikan negara Rp. 1,25 triliun dan denda pidana lebih dari Rp.2,5 triliun serta putusan yang menyatakan bahwa pembebanan pertanggunganjawaban bukan hanya kepada pekerja di lingkungan korporasi tetapi juga kepada korporasi yang harus diterapkan secara simultan sebagai cerminan respondeat superior atau "vicarious liability" (Putusan Mahkamah Agung (MA) Republik Indonesia Nomor 2239 K/PID.SUS/2012, tanggal 18 Desember 2012.). Contoh lainnya adalah putusan terhadap terdakwa S, terdakwa TKB alias W, dan terdakwa $\mathrm{E}$ yang terbukti merugikan negara sebesar Rp. 168,13 milyar dengan cara menyalahgunakan Nomor Pokok Wajib Pajak
(NPWP) dan Nomor Pengukuhan Pengusaha Kena Pajak (PKP) dari 22 perusahaan (Putusan Pengadilan Tinggi Jakarta Nomor 156/PID/2014/PT. DKI tanggal 18 Agustus 2014). Mengingat berkembangnya pelanggaran pajak yang dilakukan prinsipal melalui agen di Indonesia, adanya pengenaan sanksi terhadap wajib pajak (WP) Orang Pribadi dan atau Badan, dan perlunya pertimbangan agar cakupan pertanggungjawaban dapat diperluas, maka pengenaan pertanggungjawaban pengganti (vicarious liability) penting dan mendesak untuk diimplementasikan dalam menanggulangi dan memulihkan kerugian negara akibat penghindaran pajak (Jennifer Arlen, 1994). Terdapat dua permasalahan yang akan dikaji dalam penelitian ini. Pertama, Bagaimana pertanggungjawaban pengganti dalam pembentukan hukum pajak di Indonesia? Kedua, Bagaimana pertanggungjawaban pengganti WP dalam penegakan hukum pajak di Indonesia?

\section{Kerangka Teori}

Dalam hal terjadinya pelanggaran dalam suatu business yang mengakibatkan adanya korban, maka selayaknya regime hukum lebih berperan dalam penanggulangan atau pemulihan kerugian terhadap korban dengan memutuskan tingkat pembebanan sanksi baik kepada prinsipal, sebagai "one who authorizes another to act on his or her behalf as an agent" (Bryan A. Garner (Ed), 200), maupun kepada pelaku yang merupakan agen dari prinsipal (Lewis A. Kornhauser, 1982). Tingkat pengenaan sanksi tersebut dapat ditinjau dari hubungan principal-agent yang dikenal dengan teori keagenan (agency theory), dimana Black's Law Dictionary menegaskan keagenan sebagai "a fiduciary relationship created by express or implied contract or by law, in which one party (the agent) may act on behalf of another party (the principal) and bind that other party by words or actions" (Bryan A. Garner (Ed), 2004), yang sejalan dengan pendapat Ross yang mengungkapkan bahwa hubungan keagenan merupakan hubungan yang timbul antara dua pihak (atau lebih) dimana salah satu pihak disebut sebagai agen yang bertindak terhadap, atas nama, atau 
perwakilan dari pihak lain yang disebut prinsipal (Stephen A. Ross, 1973). Sebelum adanya teori keagenan ini, hukum melalui hukum keagenan (the law of agency) telah melakukan kajian terhadap konsekuensi hukum atas fenomena pilihan untuk bertindak melalui orang lain sebagai pengganti seseorang(Susan P. Shapiro, 2005). Hukum ini menekankan bahwa yang lebih bertanggungjawab atas pelanggaran yang dilakukan pegawai atau agen adalah business principal karena eksistensi pengawasan atau hak untuk mengawasi tindakan para agen ada pada prinsipal (Alan O. Sykes, 1981). Kemudian hukum keagenan berkembang menjadi teori keagenan dengan ide utama yang menekankan hubungan kontraktual antara prinsipal dengan agen yang harus merefleksikan organisasi yang efisien, khususnya terkait dengan informasi dan risiko timbulnya biaya-biaya, sehingga dapat menyelesaikan permasalahan asimetri informasi dalam hubungan keagenan yang disebabkan: (a) adanya konflik tujuan antara prinsipal dengan agen, dan (b) adanya kesulitan dan timbulnya biaya yang tidak sedikit yang dialami prinsipal dalam mengawasi tindakan para agen (Kathleen M. Eisenhardt,1989).

Terkait dengan tingkat pembebanan sanksi kepada prinsipal dan agen (sebagai pelaku langsung) dalam rangka pemulihan kerugian terhadap korban, diperlukan parameter untuk menguji permasalahan tersebut agar objektif dalam menerapkan pembebanan sanksi kepada prinsipal dan agen melalui mekanisme pertanggungjawaban sebagai salah satu substansi penting dalam hukum hukum administrasi dan hukum pidana. Hal ini disebabkan pertanggungjawaban, khususnya dalam hukum pidana modern saat ini, bukan hanya implementasi antara adanya asas tiada pidana tanpa kesalahan dengan asas legalitas, namun dalam hal-hal tertentu dapat memberi kemungkinan untuk menerapkan asas lainnya, seperti asas vicarious liability (Badan Pembinaan Hukum Nasional). Vicarious liability, berdasarkan Black's Law Dictionary, merupakan "liability that a supervisory party (such as an employer) bears for the actionable conduct of a subordinate or associate (such as an employee) based on the relationship between the two parties"(Bryan A. Garner (Ed), 2004), dan Kraakman mendefenisikan:

"vicarious liability is the absolute liability of one party-generally the legal 'principal' - for misconduct of another party - her 'agent' - the actor whose activities she directs. As such, traditional vicarious liability is a form of strict secondary liability, in contrast to secondary liability imposed on principals or other parties under a dutybased standardsuch as negligence"(Reinier H. Kraakman, 2016) .

Kemudian, MacIntyre menegaskan 2 (dua) kondisi terpenuhinya kategori pertanggungjawaban pengganti, yakni: "(1) the relationship between the worker and the person for whom the work was done was that of employer and employee (or sufficiently akin to the relationship of employer and employee); and (2) the employee committed the tort during the course of his employment"(Ewan MacIntyre, 2014), Sykes menyimpulkan bahwa kerangka kerja normatif pertanggung-jawaban pengganti, walaupun terdapat ketidakpastian, mengidentifikasikan faktor-faktor penting berupa kemampuan dalam mengalokasikan risiko-risiko pelanggaran yang terjadi antara prinsipal dan agen, pengaruh insentf finansial terhadap perilaku yang mencegah, dan kemampuan prinsipal dalam memonitor perilaku yang bersifat mencegah terhadap para agennya (Alan O. Sykes, 1981), dan Morgan mengibaratkan pertanggungjawaban pengganti sebagai kapak kembar (the twin axes) dari pengawasan dan kebijakan seharihari yang peranannya dapat mencakup semua hal dan ketentuan yang menegaskan tanggung jawab prinsipal atas pelanggaran agen. Pendekatan the twin axes memperhitungkan fakta bahwa pertanggungjawaban pengganti tidak hanya sesederhana berupa kumpulan diantara individu-individu, melainkan kumpulan dalam konteks kegiatan-kegiatan yang dimaksudkan untuk kemanfaatan (Phillip Morgan, 2012). Lebih rinci, Jones 
menjelaskan bahwa prinsipal bersama-sama dengan pegawai yang melakukan pelanggaran secara bersama-sama bertanggung jawab atas terjadinya pelanggaran yang terjadi sepanjang melaksanakan tugas di lingkup principal business, sedangkan korban (the injured party atau the third party) "...can take action against the employee or alternatively sue the employer, who is vicariously liable for his employee's actions. The third party is more likely to sue the employer, because the employer will usually be in a better financial position to pay compensation because he is insured"' (Lucy Jones, 2013).

\section{Metode Penelitian}

Penelitian ini menggunakan metode yuridis normatif yang dimulai dari inventarisasi peraturan perundangundangan, hukum in concreto, asas hukum, dan perbandingan hukum terkait pertanggungjawaban pengganti dalam perspektif hukum pajak di Indonesia dengan cara meneliti bahan pustaka atau data sekunder berupa bahan hukum primer, sekunder, dan tersier (Soerjono Soekanto et al., 2007). Bahan hukum primer terdiri dari bahan-bahan hukum yang mengikat berupa peraturan perundang-undangan yang berhubungan dengan pajak yang dikelola Direktorat Jenderal Pajak (DJP) dan pertanggungjawaban pengganti. Bahan hukum sekunder antara lain mempergunakan rancangan undang-undang, textbooks, pendapat ahli hukum, artikel, hasil-hasil seminar, dan hasil penelitian di bidang hukum dan perpajakan. Sedangkan bahan hukum tersier merupakan bahan-bahan yang menunjang informasi bahan hukum primer dan sekunder, seperti kamus, encyclopedia, dan bahan-bahan hukum tersier lain. Data sekunder yang diperoleh diteliti dengan pendekatan deskriptif - komparatif preskriptif, (Soerjono Soekanto, 2010) dianalisis dengan kritis secara yuridis kualitatif, yaitu berdasarkan perundangundangan yang tidak bertentangan dengan perundang-undangan yang lain, dengan memperhatikan hierarki perundangundangan, mewujudkan kepastian hukum, mencari hukum yang hidup di dalam masyarakat, baik yang tertulis maupun yang tidak tertulis (Soerjono Soekanto, 2010), kemudian disusun secara sistematis, dan ditarik suatu simpulan.

\section{B. Hasil dan Pembahasan}

1. Pertanggungjawaban Pengganti dalam Pembentukan Hukum Pajak di Indonesia

Pertanggungjawaban pengganti merupakan merupakan salah satu isu sentral dalam hukum (pajak) yang harus dipahami prinsipal dan agen dalam yang menjalankan hak dan kewajiban hukum (pajak) karena mengacu pada tingkat pengenaan sanksi yang telah ditetapkan dalam peraturan yang berlaku (V. Lee Hamilton, 1978) yang tidak hanya dikenakan terhadap pelaku pelanggaran tetapi juga terhadap setiap orang yang secara hukum terkait dengan pelanggaran tersebut (Jimly Asshiddiqie dan Ali Safa'at,2006).

Melekatnya pertanggungjawaban pengganti dalam hubungan keagenan tidak dapat terlepasa dari pendapat yang menyatakan bahwa efisiennya suatu usaha dapat terjadi bila prinsipal mengawasi perilaku pegawainya dan sekaligus sebagai sarana untuk meningkatkan tingkat keperdulian prinsipal terhadap pegawainya (C. Y. Cyrus Chu dan Yingyi Qian, 1995). Pengawasan prinsipal, dalam konteks teori keagenan, tidak dapat terlepas dari terjalinnya hubungan kontratual, yang menurut Walker, didasarkan pada adanya ketidakpastian sehingga prinsipal berusaha mengikat para agennya melalui kontrak yang didasarkan atas tiga pertimbangan, yakni: (1) kontrak dibuat dengan cukup menarik untuk mencegah agen bekerja ditempat lain, (2) kontrak harus dirumuskan dalam usaha tertentu yang memberikan agen suatu insentif yang hanya diperoleh bilamana telah mencapai target tertentu, dan (3) kontrak semestinya dapat dilaksanakan berdasarkan informasi yang dapat ditinjau oleh prinsipal dan agen (Martin Walker, 1989).

Melalui hubungan kontraktual tersebut, dapat diuji tingkat pembebanan sanksi kepada prinsipal dan agen (sebagai pelaku langsung) dalam hal terjadinya pelanggaran yang 
dilakukan agen yang memerlukan pemulihan kerugian terhadap korban melalui pertanggungjawaban pengganti. Implementasi pertanggungjawaban pengganti yang dimaksud haruslah tetap mengacu pada prinsip keadilan dan kewajaran sehingga diperlukan parameter tertentu dalam pelaksanaannya. Beberapa istilah penyebutan parameter tersebut dikenal dengan penyebutan "sufficiently close connection", "so closely connected", atau "standard of care". Pengujian "sufficiently close connection" atau "so closely connected" mencakup ada tidaknya manfaat yang diperoleh prinsipal atas kegiatan agennya, ada tidaknya job description yang telah ditetapkan oleh prinsipal ketika suatu tindakan dilakukan oleh agennya, dan ada tidaknya pengelolaan risiko yang dibuat oleh prinsipal dalam kerangka kerja para agennya (Nicholas J. McBride, 2013) yang dikenal sebagai konsep "enterprise risk" yang artinya prinsipal dianggap telah menyeleksi pegawainya, mendelegasikan tugas-tugas dan meminta manfaat dari kinerja pegawainya, sehingga seharusnya telah memprediksi dan menerima risiko terkait pegawaipegawainya, seperti adanya tindakan pegawai diluar batas kewenangannya dan adanya pegawai yang menentang instruksi-instruksi kerja yang ada (Robert Weekes, 2004). Pengujian "standar of care" dilakukan berdasarkan tujuh faktor berikut:

(1) limitations on contractual form that derive from imprecise monitoring of agent care;

(2) conflicts of interest between principal and agent; (3) costs of screening employees on the basis of carefulness; (4) partial control by the enterprise of the probability of an accident; (5) limited liabilty of the agent; (6) additional non-labor market impediments to the contractual form; and (7) differences in court ant enterprise ability to hold agents responsible" (Lewis A. Kornhauser, 1982).

Selain penjelasan diatas, Meyers mengingatkan bahwa walaupun pertanggungjawaban pengganti merupakan justifikasi untuk memaksa prinsipal untuk melakukan ganti rugi (termasuk pertanggungjawaban hukum) atas perbuatan agen yang terjadi dalam lingkup pekerjaan, dan walaupun pertanggungjawaban ini dapat berdampingan dengan regime pertanggungjawaban berdasarkan kesalahan, namun terdapat resistensi yang disebabkan empat hal berikut:

"First, the theory is flatly contradicted by high case authority. Second, the contractual model of vicarious liability cannot explain how vicarious liability could be a rule of law since if the theory were true every employer would henceforth explicitly exclude the right to indemnity in every contract of employment. Third, the theory cannot account for the leading cases, both classic and modern, that have posited liability for those intentional torts which could in no way be seen as good faith efforts to perform the contract of employment. And fourth, the theory is under-inclusive since it cannot explain why vicarious liability is imposed in noncontractual situations" (J. W. Neyers, 2005).

Dalam ketentuan UU pajak di Indonesia, prinsipal dan agen tidak sepenuhnya mengetahui posisi masingmasing dalam memnuhi hak dan kewajiban perpajakannya karena ketidakpahaman makna subjek pajak yang tidak semua UU pajak menegaskan secara eksplisit, sebagaimana UU No. 36 Tahun 2008 tentang Pajak Penghasilan (UU PPh) menegaskan subjek pajak dalam negeri dan luar negeri yang meliputi orang pribadi, warisan yang belum terbagi sebagai satu kesatuan menggantikan yang berhak, badan, dan bentuk usaha tetap (BUT) (Pasal 2 ayat (1) dan ayat (3) UU PPh). Sedangkan UU pajak lainnya seperti UU No. 16 Tahun 2009 tentang Ketentuan Umum dan Tata Cara Perpajakan (UU KUP) hanya mencantumkan kata WP sebagai orang pribadi atau badan yang mempunyai hak dan kewajiban perpajakan (Pasal 1 angka (2) UU KUP), UU No. 42 Tahun 2009 tentang Pajak Pertambahan Nilai Barang dan Jasa dan Pajak Penjualan Atas Barang Mewah (UU PPN) menyebutkan PKP sebagai Pengusaha 
yang melakukan penyerahan Barang Kena Pajak dan/atau penyerahan Jasa Kena Pajak (Pasal 1 angka (15) UU PPN), dan UU No. 19 Tahun 2000 tentang Penagihan Pajak dengan Surat Paksa (UU PPSP) menyebutkan Penanggung Pajak sebagai orang pribadi atau badan yang bertanggung jawab atas pembayaran pajak, termasuk wakil yang menjalankan hak dan memenuhi kewajiban WP (Pasal 1 angka (28) UU KUP dan Pasal 1 angka (3) UU PPSP).

Dalam UU KUP telah menegaskan bahwa setiap WP yang telah memenuhi persyaratan subjektif dan objektif wajib menjadi WP (Pasal 2 ayat (1) UU KUP) serta diwajibkan untuk mengisi, menandatangani dan menyampaikan Surat Pemberitahuan (SPT) dengan benar, lengkap, dan jelas (Pasal 4 ayat (1) UU KUP). WP juga dapat menunjuk seorang kuasa khusus dengan surat kuasa khusus untuk mengisi dan menandatangani SPT (Pasal 4 ayat (3) UU KUP). Khusus WP Badan, SPT harus ditandatangani oleh pengurus atau direksi (Pasal 4 ayat (2) UU KUP) atau seorang kuasa dengan surat kuasa khusus dimana pada Pasal 32 ayat (1) dan ayat (2) UU KUP ditegaskan bahwa yang menjadi wakil WP, yaitu pengurus dalam hal WP Badan, bertanggung jawab secara pribadi dan/atau secara renteng atas pembayaran pajak yang terutang. Tanggung jawab renteng tersebut dapat dikecualikan apabila wakil WP tersebut dapat membuktikan dan meyakinkan bahwa dalam kedudukannya, menurut kewajaran dan kepatutan, tidak mungkin dimintai pertanggungjawaban (Penjelasan Pasal 32 ayat (2) UU KUP). Pengecualian tersebut menunjukkan bahwa pertanggungjawaban atas pembayaran pajak dapat dialihkan kepada pihak lain seperti komisaris dan pemegang saham mayoritas atau pengendali dan atau orang yang ternyata berwenang menentukan kebijakan dan atau mengambil keputusan dalam perusahaan dan atau berwenang menandatangani kontrak/ perjanjian dan atau menandatangani cek/giro (Penjelasan Pasal 32 ayat (4) UU KUP). Adanya Pasal 32 UU KUP yang diperkuat dengan definisi WP dalam konteks UU KUP dan UU PPh, dan defenisi Penanggung Pajak dalam konteks UU PPSP memperlihatkan bahwa pertanggungjawaban pengganti dalam peraturan perpajakan di Indonesia masih diatur secara implisit. Tidak seperti ius constituendum pada Pasal 39 ayat (2) Rancangan Kitab Undang-Undang Hukum Pidana (KUHP) 2015-2016 yang secara eksplisit menegaskan adanya pertanggungjawaban pengganti yang menyatakan "Dalam hal ditentukan oleh UU, setiap orang dapat dipertanggungjawabkan atas tindak pidana yang dilakukan oleh orang lain". Untuk perbandingan, beberapa negara telah secara eksplisit mengatur pertanggungjawaban pengganti dalam ius constitutum-nya seperti negara Inggris, Amerika Serikat, India, dan Kanada.

Dalam ketentuan pidana di Inggris, pertanggungjawaban pengganti diberlakukan terhadap jenis tindak pidana tertentu yang terhadap delik-deliknya mensyaratkan kualitas dan adanya hubungan antara buruh dan majikan (Muladi dan Dwidja Priyatno, 2010). Bahkan negara Amerika Serikat dengan tegas telah mengatur dan menguraikan kriteria pertanggungjawaban pengganti dalam Bagian 2 Pasal 07 Model Penal Code nya, yakni: (a) Tindak pidana ringan yang hanya dikenakan pidana denda dan UU secara jelas menyebutkan pertanggungjawaban pidana tersebut terjadi jika dilakukan oleh orang yang bertindak atas nama korporasi di dalam kewenangannya sebagai pegawai; atau (b) Kelalaian terhadap tugas tertentu yang ditentukan UU yang harus dilakukan oleh korporasi; atau (c) Tindak pidana yang disetujui, dilakukan atau secara lalai disetujui oleh dewan komisaris atau dewan direksi yang bertindak atas nama korporasi dalam kewenangannya sebagai pegawai (Romli Atmasasmita, 2009).

Di India, pertanggungjawaban pengganti dalam ketentuan pajaknya diatur dalam Section 278B Indian Income Tax Act 1961-2016 yang dapat diterapkan pada perusahaan yang bertanggung jawab secara pidana denda atas pelanggaran pegawainya dalam lingkup pekerjaan, dan pada pegawaipegawai utama/kunci yang bertanggung jawab secara pidana atas pelanggaran perusahaan sebagaimana ditegaskan bahwa jika sebuah perusahaan melakukan pelanggaran, setiap orang, ketika 
pelanggaran dilakukan, dianggap bersalah dan bertanggung jawab, kecuali dapat membuktikan tidak bersalah atau telah melaksanakan uji tuntas (due diligence) untuk mencegah terjadinya pelanggarant. Adapun kutipan selengkapnya adalah:

"(1) Where an offence under this Act has been committed by a company, every person who, at the time the offence was committed, was in charge of, and was responsible to, the company for the conduct of the business of the company as well as the company shall be deemed to be guilty of the offence and shall be liable to be proceeded against and punished accordingly: Provided that nothing contained in this sub-section shall render any such person liable to any punishment if he proves that the offence was committed without his knowledge or that he had exercised all due diligence to prevent the commission of such offence.

(2) Notwithstanding anything contained in sub-section (1), where an offence under this Act has been committed by a company and it is proved that the offence has been committed with the consent or connivance of, or is attributable to any neglect on the part of, any director, manager, secretary or other officer of the company, such director, manager, secretary or other officer shall also be deemed to be guilty of that offence and shall be liable to be proceeded against and punished accordingly. (3) Where an offence under this Act has been committed by a person, being a company, and the punishment for such offence is imprisonment and fine, then, without prejudice to the provisions contained in sub-section (1) or sub-section (2), such company shall be punished with fine and every person, referred to in sub-section (1), or the director, manager, secretary or other officer of the company referred to in sub-section (2), shall be liable to be proceeded against and punished in accordance with the provisions of this Act" (Section 278B (1), of the Indian ITA 1961-2016).

Dalam ketentuan pajak di Kanada, penerapan pertanggungjawaban pengganti diatur pada Section 160.3 Subsection (3) dan Section 160.4 Subsection (4) Canadian Income Tax Act (Government of Canada, 2017) sebagaimana diamandemen terakhir pada tanggal 1 April 2017. Adapun kutipan langsung Section 160.3 Subsection (3) adalah: "If a taxpayer and another person have, by virtue of subsection (1), become jointly and severally, or solidarily, liable in respect of part or all of a liability of the taxpayer under this Act, the following rules apply: (a) a payment by the other person on account of the other person's liability shall to the extent thereof discharge their liability; but (b) a payment by the taxpayer on account of the taxpayer's liability discharges the other person's liability only to the extent that the payment operates to reduce the taxpayer's liability to an amount less than the amount in respect of which the other person was, by subsection (1), made jointly and severally, or solidarily, liable."

Dalam Section 160.3 Subsection (1) Canadian Income Tax Act adalah yang mengatur tentang terdapatnya sejumlah tertentu yang termasuk dalam penghasilan seorang WP yang diterima oleh seseorang yang mana WP tersebut melakukan transaksi yang tidak sesuai dengan harga wajar ( $\mathrm{arm}^{\mathrm{s}} \mathrm{s}$ length) sehingga orang tersebut dengan WP tersebut secara bersama-sama dan dengan sangat harus bertanggungjawab atas pembayaran pajak WP yang seharusnya terutang. Kemudian pada Section 160.4 Subsection (4) diatur:

"If a corporation and another person have, because of subsection (1) or (2), become jointly and severally, or solidarily, liable in respect of part or all of a liability of the corporation under this Act: (a) a payment by the other person on account of that person's liability shall to the extent thereof discharge their liability; and (b) a payment by the corporation on account of the corporation's liability discharges the other person's liability only to the extent that the payment operates to reduce the corporation's liability to an amount less than the amount in respect of which the other person was, by subsection (1) 
or (2), as the case may be, made jointly and severally, or solidarily, liable."

Maksud Section 160.4 Subsection (1) dan (2) Canadian Income Tax Act adalah yang berkenaan dengan properti yang dialihkan oleh perusahaan (transferor) yang tidak sesuai dengan prinsip kelaziman harga ( $a r m$ 's length) kepada seorang WP (transferee), maka WP dengan perusahaan tersebut secara bersama-sama dan dengan sangat harus bertanggungjawab atas pembayaran pajak perusahaan yang lebih kecil dari yang seharusnya terutang.

Adanya pertanggungjawaban pengganti di bidang perpajakan seperti yang ada di India dan Kanada hampir identik dengan hukum administrasi pajak di Indonesia yang dikenal dengan istilah beneficial owner (BO) (Abdul Ficar Hadjar, et. al., 2014) dan hubungan istimewa (related party) sebagaimana diatur dalam Pasal 18 ayat (3b), ayat (3c), dan ayat (3d) UU PPh. Pada Pasal 18 ayat (3b) UU PPh dinyatakan bahwa WP yang membeli saham atau aktiva perusahaan melalui pihak lain atau special purpose company (SPV), dapat ditetapkan sebagai pihak yang sebenarnya melakukan pembelian tersebut sepanjang WP yang bersangkutan mempunyai hubungan istimewa dengan pihak lain atau badan tersebut dan terdapat ketidakwajaran penetapan harga. Pada Pasal 18 ayat (3c) UU $\mathrm{PPh}$ diatur bahwa penjualan atau pengalihan saham perusahaan antara (conduit company atau $S P V$ ) yang didirikan atau bertempat kedudukan di tax haven country yang mempunyai hubungan istimewa dengan badan yang didirikan atau bertempat kedudukan di Indonesia atau BUT di Indonesia dapat ditetapkan sebagai penjualan atau pengalihan saham badan yang didirikan atau bertempat kedudukan di Indonesia atau BUT di Indonesia. Dan pada Pasal 18 ayat (3d) UU PPh diatur bahwa besarnya penghasilan yang diperoleh WP orang pribadi dalam negeri dari pemberi kerja yang memiliki hubungan istimewa dengan perusahaan lain yang tidak didirikan dan tidak bertempat kedudukan di Indonesia dapat ditentukan kembali, dalam hal pemberi kerja mengalihkan seluruh atau sebagian penghasilan WP orang pribadi dalam negeri tersebut ke dalam bentuk biaya atau pengeluaran lainnya yang dibayarkan kepada perusahaan yang tidak didirikan dan tidak bertempat kedudukan di Indonesia tersebut.

Selain secara hukum administratif di bidang perpajakan, secara ketentuan pidana di bidang perpajakan di Indonesia ternyata masih tidak secara eksplisit menerapkan pertanggungjawaban pengganti. Hal ini dapat dilihat dari aturan pada Pasal 13A dan Pasal 44B ayat (2) UU KUP. Pasal 13A UU KUP merupakan tindak lanjut dari terbuktinya perbuatan pada Pasal 38 UU KUP namun karena merupakan perbuatan pertama sekali dari unsur "setiap orang" yang karena kealpaanya melakukan delik menjadi pertanggungjawaban WP dalam bentuk pelunasan kekurangan pembayaran pajak beserta sanksi administrasi kenaikan sebesar $200 \%$ dari jumlah pajak yang kurang dibayar. Begitu halnya dengan Pasal 44B ayat (2) UU KUP yang juga merupakan pengadopsian pertanggungjawaban pengganti dalam ketentuan pidana di bidang perpajakan sebagai wujud dari ultimum remedium hukum pajak dimana unsur dari "setiap orang" yang memenuhi delik Pasal 39 ayat (1), ayat (2), ayat (3), dan Pasal 39A UU KUP menjadi pertanggungjawaban WP dalam bentuk pelunasan utang pajak beserta denda sebesar empat kali jumlah pajak yang tidak atau kurang dibayar, atau yang tidak seharusnya dibayar.

\section{Pertanggungjawaban Pengganti dalam Penegakan Hukum Pajak di Indonesia}

Hukum, yang kaidah-kaidahnya dirumuskan secara eksplisit dalam wujud peraturan, dibuat untuk dilaksanakan sehingga didalamnya diperlukan tindakantindakan berupa penegakan hukum (Satjipto Rahardjo, 2009) karena mempunyai hubungan yang sangat erat dengan kecenderungan-kecenderungan yang ada pada masyarakat (Satjipto Rahardjo, 2009). Dalam lapangan hukum pajak, salah satu kecenderungan permasalahan hukum adalah maraknya penghindaran pajak yang mengarah ke penggelapan pajak sehingga diperlukan adanya pemulihan kerugian negara melalui pertanggungjawaban 
pengganti terhadap penerima manfaat penghindaran pajak tersebut. Penegakan hukum pajak, yang dalam hal ini dilaksanakan oleh DJP, agar dapat dilaksanakan maka harus mempunyai legalitas sebagai wujud kepastian hukum sebagaimana konsepsi grundnorm (Bryan A. Gardner, 2004) Hans Kelsen menegaskan bahwa sistem hukum itu merupakan suatu hierarki dari hukum dimana suatu ketentuan hukum bersumber pada ketentuan yang lebih tinggi. Pemahaman kepastian hukum pajak juga tidak dapat terlepas dari kedudukannya sebagai bagian dari Hukum Administrasi Negara (HAN) (C.S.T. Kansil dan Christine S.T. Kansil, 2007) yang didalamnya terdapat sanksi administratisi, baik dalam bentuk bunga dan atau denda, dan sanksi pidana, yang dikualifikasikan sebagai kejahatan (Rochmat Soemitro, 1992). Adapun implementasi grundnorm dalam penegakan hukum pajak di Indonesia dapat dilihat pada Pasal 23A Perubahan Keempat UndangUndang Dasar Negara Republik Indonesia Tahun 1945 (UUD RI 1945) (Pasal 23A Perubahan Keempat UUD RI 1945) yang menyatakan bahwa pajak dan pungutan lain yang bersifat memaksa untuk keperluan negara diatur dengan UU. Selanjutnya, pengaturan dalam pasal-pasal pidana pajak dapat dilihat pada Pasal 38, Pasal 39, Pasal 39A, Pasal 41, Pasal 41A, Pasal 41B, Pasal $41 \mathrm{C}$ dan Pasal 43 UU KUP, dan Pasal 41A UU PPSP.

Adanya pertanggungjawaban pengganti dalam ketentuan perpajakan, menurut Suhariyanto, menunjukkan bahwa putusan pemidanaan tanpa didakwakan adalah sudah tepat karena merupakan manifestasi prinsip penyelengaraan peradilan secara sederhana, murah, dan cepat. Selain itu, tujuannya adalah untuk pemulihan kerugian pendapatan negara yang berasal dari pajak yang walaupun dilakukan secara individual oleh terdakwa, namun karena perbuatan tersebut dalam rangka pelaksanaan fungsional yang mewakili dan semata-mata untuk kepentingan korporasi maka tidaklah adil jika tanggung jawab pidana hanya dibebankan kepada terdakwa sebagai individu yang memang tidak akan mungkin mampu menggantinya. Sehingga adalah logis jika korporasi diputus tanpa didakwakan untuk membayar denda pidana tersebut (Budi Suhariyanto, 2017).

Selain itu, adanya pertanggungjawaban pidana dari unsur "setiap orang" yang dilakukan WP Badan yang dalam konteks pidana perpajakan belum mengatur subjek hukum korporasi menjadi pertanggungjawaban WP dalam bentuk pelunasan utang pajak beserta denda adalah sejalan dengan Peraturan MA (PERMA) Nomor 13 Tahun 2016 yang menegaskan bahwa korporasi dapat dimintakan pertanggungjawaban pidana (Pasal 4 Peraturan Mahkamah Agung Republik Indonesia), dan Peraturan Jaksa Agung Nomor PER-028/A/JA/10/2014 yang menegaskan adanya kewenangan Jaksa dalam melakukan penyelidikan, penyidikan, dan penuntutan pidana terhadap korporasi (Pasal 1 dan Pasal 2 Peraturan Jaksa Agung). Bahkan mengingat pentingnya pemberlakuan tanggung jawab pidana korporasi, aturan secara tertulis telah diusulkan dalam bentuk Rancangan KUHP 2015-2016 yang merumuskan bahwa tindak pidana yang dilakukan suatu korporasi dapat dipertanggungjawabkan bersama-sama pengurus apabila pengurus yang memiliki jabatan penting dan atau orang-orang yang mempunyai kedudukan fungsional dalam struktur organisasi yang bertindak baik secara individual atau atas nama badan hukum untuk dan atas nama badan hukum, berdasarkan hubungan kerja atau berdasarkan hubungan lain, dalam lingkup badan hukum tersebut, dan Pasal 118 ayat (2) RUU KUP (Badan Pembinaan Hukum Nasional Kementerian Hukum dan HAM Republik Indonesia) yang mengatur pemidanaan di bidang perpajakan terhadap Badan apabila tindak pidana pajak tersebut: (a) dilakukan atau diperintahkan oleh pengurus; (b) dilakukan dalam rangka pemenuhan maksud dan tujuan Badan; (c) dilakukan sesuai dengan tugas dan fungsi pelaku atau pemberi perintah; dan (d) dilakukan dengan maksud memberikan manfaat bagi Badan.

\section{Simpulan}

Penelitian ini menghasilkan dua kesimpulan. Pertama, Pertanggungjawaban pengganti dalam peraturan perundang- 
undangan perpajakan di Indonesia belum diatur secara eksplisit khususnya dalam ketentuan pidana pajak, padahal penghindaran pajak dengan memanfaatkan keberadaan agen untuk penghindaran pajak prinsipal semakin berkembang. Sehingga penting dan mendesak agar dilakukan tindakan pencegahan dalam menanggulangi dan atau memulihkan kerugian pendapatan negara dari pajak melalui pengaturan secara tegas pertanggungjawaban pengganti dan kriterianya dalam peraturan perundangundangan perpajakan di masa yang akan datang. Diharapkan juga agar kriteria tersebut dapat mengantisipasi hubungan keagenan yang non kontraktual, dapat menjangkau pemegang otoritas yang paling tinggi di perusahaan seperti pemegang saham, direksi, dan komisaris yang memang menerima manfaat atas penghindaran pajak yang terjadi, dan dapat mengantisipasi adanya kontrak kerja yang seolah-olah membebankan ganti rugi terhadap pegawai perusahaan padahal bukan pegawai tersebut yang menerima manfaat atas terjadinya penghindaran pajak tersebut. Kedua, Pertanggungjawaban pengganti dalam penegakan hukum pajak di Indonesia khususnya yang menyangkut tindak pidana pajak yang terjadi dalam hubungan keagenan hampir tidak pernah menyentuh penerima manfaat, yakni prinsipal. Diharapkan para penegak hukum pajak dapat mempelajari putusan hakim terkait pidana pajak, seperti putusan kasasi MA No. 2239 K/PID.SUS/20122, yang membuat putusan pemidanaan tanpa didakwakan terhadap prinsipal untuk membayar kerugian pendapatan negara dari sektor pajak sekaligus dengan denda pidana. Agar pertanggungjawaban pengganti lebih memiliki legalitas dan kepastian hukum dalam penerapan penegakan hukum pajak di Indonesia khususnya dalam penanganan tindak pidana pajak yang bertujuan untuk dapat menanggulangi dan memulihkan kerugian pada pendapatan negara, diharapkan adanya perluasan pengertian "setiap orang" dalam delik pidana pajak yang mencakup manusia dan korporasi.

\section{DAFTAR PUSTAKA}

Arlen Jennifer, "The Potentially Perverse Effects of Corporate Criminal Liability", The Journal of Legal Studies, Vol.23, No. 2, Juni 1994.

Asshiddiqie Jimly dan A. Safa'at, 2006, Teori Hans Kelsen Tentang Hukum, Kons Press, Jakarta.

Atmasasmita Romli, 2009, Perbandingan Hukum Pidana Kontemporer, Penerbit Fikahati Aneska, Jakarta. "Draft Naskah Akademik Rancangan UU tentang KUHP", tersedia di w $\quad$ e $\quad b \quad s \quad$ i $\quad t \quad e$ http://www.bphn.go.id/data/docume nts/naskah akademik tentang_kuh p_dengan lampiran.pdf, diakses pada tanggal 27 Mei 2016.

Chyz James A. dan S. D. White, "The Association between Agency Conflict and Tax Avoidance: A Direct Approach", Advances in Taxation, Vol. 21, 2014.

Chu C. Y. Cyrus dan Y. Qian, "Vicarious Liability under a Negligence Rule", International Review of Law and Economics, Vol. 15, 1995.

Desai Mihir A. dan D. Dharmapala, "Corporate Tax Avoidance and Firm Value", The Review of Economics and Statistics, Vol. 91, No. 3, Agustus 2009.

Eisenhardt Kathleen M., "Agency Theory: An Assessment and Review", Academy of Management Review, Vol. 14, No. $1,1989$.

Gardner Bryan A., 2004, Black's Law Dictionary, Thomson West, US.

Government of Canada, tersedia di website http://1aws-1ois.justice.gc. c a/eng/acts/i-3.3/page 190.html\#docCont, diakses pada tanggal 25 April 2017.

Government of Indian, The Indian Income Tax Act 1961-2016, tersedia di website http://www.incom etaxindia.gov.in/pages/acts/incometax-act.aspx, diakses pada tanggal 6 September 2016.

Hadjar Abdul Ficar, et.al., 2014, Menghukum Pengemplang Pajak: Hasil 
Chyz James A. dan S. D. White, "The Association between Agency Conflict and Tax Avoidance: A Direct Approach", Advances in Taxation, Vol. 21, 2014.

Chu C. Y. Cyrus dan Y. Qian, "Vicarious Liability under a Negligence Rule", International Review of Law and Economics, Vol. 15, 1995.

Desai Mihir A. dan D. Dharmapala, "Corporate Tax Avoidance and Firm Value", The Review of Economics and Statistics, Vol.91, No. 3, Agustus 2009.

Eisenhardt Kathleen M., "Agency Theory: An Assessment and Review", Academy of Management Review, Vol. 14, No. 1, 1989.

Gardner Bryan A., 2004, Black's Law Dictionary, Thomson West, US.

Government of Canada, tersedia di website http://laws-1ois.justice.gc.ca/e ng/acts/i-3.3/page-190.html\#docCont, diakses pada tanggal 25 April 2017.

Government of Indian, The Indian Income Tax Act 1961-2016, tersedia di website http://www.incometaxindia.gov.in/ pages/acts/income-tax-act.aspx, diakses pada tanggal 6 September 2016.

Hadjar Abdul Ficar, et.al., 2014, Menghukum Pengemplang Pajak: Hasil Eksaminasi Publik atas Putusan Mahkamah Agung Dalam Perkara Tindak Pidana Pajak dengan Terdakwa Suwir Laut, The Indonesian Legal Resource Center dan Indonesian Corruption Watch, Jakarta.

Hamilton V. Lee, "Who is Responsible? Toward a Social Psychology of Responsibility", Social Psychology, Vol. 41, No. 4, 1978.

Jones Lucy, 2013, Introduction to Business Law, Oxford, Oxford University Press.

Kansil C.S.T. dan C.S.T. Kansil, 2007, Latihan Ujian: Pengantar Hukum Indonesia, Sinar Grafika, Jakarta.

Kejaksaan Agung R.I., Peraturan Jaksa Agung No. PER-028/A/JA/10/2014 tanggal 1 Oktober 2014 Tentang Pedoman Penanganan Perkara Pidana dengan Subjek Hukum Korporasi.

Kofman Fred dan J. Lawarree, "Collusion in Hierarchical Agency", Econometrica, Vol. 61, No. 3, Mei 1993.
Kornhauser Lewis A., "An Economic Analysis of the Choice Between Enterprise and Personal Liability for Accidents", California Law Review, Vol. 70, Issue 6, Desember 1982.

Kraakman Reinier H., "Gatekeepers: The Anatomy of a Third-Party Enforcement Strategy", Journal of Law, Economics, and Organization, Vol. 2, No. 1, 1986.

Laffont Jean-Jacques dan J. Tirole, "Cost Padding, Auditing and Collusion", Annales d'Economie et de Statistique, No. 25/26, 1992.

Mahkamah Agung R. I., Putusan Kasasi Mahkamah Agung No. 2239 K/PID.SUS/2012 tanggal 18 Desember 2012.

Putusan Pengadilan Tinggi Jakarta No. 156/PID/2014/PT. DKI tanggal 18 Agustus 2014.

Peraturan Mahkamah Agung Republik Indonesia No. 13 Tahun 2016 tanggal 21 Desember 2016 Tentang Tata Cara Penanganan Perkara Tindak Pidana oleh Korporasi.

McBride Nicholas J., "Vicarious Liability in England and Australia", The Cambridge Law Journal, Vol. 62, No. 2, Juli 2003.

Morgan Phillip, "Recasting Vicarious Liability", Cambridge Law Journal, Vol. 71, No. 3, 2012.

Muladi dan D. Priyatno, 2010 , Pertanggungjawaban Pidana Korporasi, Kencana, Jakarta.

Neyers J. W., "A Theory of Vicarious Liability", Alberta Law Review, Vol. 43, No. 2, 2005.

Privileggi Fabio, C. Marchese, dan A. Cassone, "Agent's Liability vs Principal's Liability when Attitudes Toward Risk Differ", International Review of Law and Economics, Vol. 21, 2001.

Rahardjo Satjipto, 2009, Penegakan Hukum: Suatu Tinjauan Sosiologis, Yogyakarta, Genta Publishing.

Ross Stephen A., "The Economic Theory of Agency: The Principal's Problem", The American Economic Review, Vol.63, No. 2, Mei 1973.

Shapiro Susan P., "Agency Theory", Annual Review Sociology, Vol. 31, 2005. 
Tentang Tata Cara Penanganan Perkara Tindak Pidana oleh Korporasi.

McBride Nicholas J., "Vicarious Liability in England and Australia", The Cambridge Law Journal, Vol. 62, No. 2 , Juli 2003.

Morgan Phillip, "Recasting Vicarious Liability", Cambridge Law Journal, Vol. 71, No. 3, 2012.

Muladi dan D. Priyatno, 2010 , Pertanggungjawaban Pidana Korporasi, Kencana, Jakarta.

Neyers J. W., "A Theory of Vicarious Liability", Alberta Law Review, Vol. 43, No. 2, 2005.

Privileggi Fabio, C. Marchese, dan A. Cassone, "Agent's Liability vs Principal's Liability when Attitudes Toward Risk Differ", International Review of Law and Economics, Vol. 21, 2001.

Rahardjo Satjipto, 2009, Penegakan Hukum: Suatu Tinjauan Sosiologis, Yogyakarta, Genta Publishing.

Ross Stephen A., "The Economic Theory of Agency: The Principal's Problem", The American Economic Review, Vol. 63, No. 2, Mei 1973.

Shapiro Susan P., "Agency Theory", Annual Review Sociology, Vol. 31, 2005.

Soekanto Soerjono, et al., 2007, Penelitian Hukum Normatif: Suatu Tinjauan Singkat, PT. Rajagrafindo Persada, Jakarta.

Soekanto Soerjono, 2010, Pengantar Penelitian Hukum, UI Press, Jakarta.

Soemitro Rochmat, 1992, Pengantar Singkat Hukum Pajak, Eresco, Bandung.

Suhariyanto Budi, "Putusan Pemidanaan terhadap Korporasi Tanpa Didakwakan dalam Perspektif Vicarious Liability: $\mathrm{Kaj}$ ian Putusan No. 2239 K/PID.SUS/2012", Jurnal Yudisial, Vol. 10, No. 1, 2017.

Sykes Alan O., "An Efficiency of Vicarious Liability under the Law of Agency", The Yale Law Journal, Vol. 91, No. 1, Nopember 1981.

Walker Martin, "Agency Theory: A Falsificationist Perspective", Accounting Organizational and Society, Vol. 14, No. 5/6, 1989.
Weekes Robert, "Vicarious Liability for Violent Employees", Cambridge Law Journal, Vol. 63, No. 1, Maret 2004.

\section{Undang-Undang}

Republik Indonesia, Undang-Undang Dasar Negara Republik Indonesia Tahun 1945.

Undang-Undang No. 6 Tahun 1983 tentang Ketentuan Umum dan Tata Cara Perpajakan Sebagaimana Telah Diubah Terakhir Dengan UndangUndang No. 16 Tahun 2009. Undang-Undang No. 7 Tahun 1983 tentang Pajak Penghasilan Sebagaimana Telah Diubah Terakhir Dengan UndangUndang No. 36 Tahun 2008.

Undang-Undang No. 8 Tahun 1983 tentang Pajak Pertambahan Nilai dan Pajak Penjualan Atas Barang Mewah Sebagaimana Telah Diubah Terakhir Dengan UndangUndang No. 42 Tahun 2009.

Undang-Undang No. 19 Tahun 1997 tentang Penagihan Pajak Dengan Surat Paksa Sebagaimana Telah Diubah Dengan UndangUndang No. 19 Tahun 2000. 